\title{
Science Kits as Resource: Some Pedagogical Considerations
}

\author{
Dr. Nirupma Jaimini \\ Department of Education, University of Delhi, India
}

\begin{abstract}
To generate excitement and interest in science through 'hands-on' activities, the role of science kits has long been recognized. However, in the Indian context and in many other developing countries, science kits as a learning aid are being used in a sporadic manner, not holding much fascination for the teacher. The upcoming curricula for teacher education envisage the teacher to be actively involved in the 'development' of learner-centric and contextualized resource material. This builds up a case for positing a shift in thrust from using available science kits to adapting or developing them instead. It was in this background that a research project was undertaken by a team of science teachers and teacher educators. Twelve science kits were sampled from diverse sources across the country and were worked upon for their 'pedagogic usefulness' and subsequently, a framework was evolved. The framework was further worked upon in schools and teacher education institutions for wider outreach and applicability. Based on the evolved framework, five new science kits were developed by the teachers. Inherent in this approach was the effort to empower the science teacher to move from being a 'user' of existing science kits to becoming an 'adapter and developer' of them.

Keywords : hands-on activities, pedagogic usefulness, resource material, science kits
\end{abstract}

\section{Introduction}

Popularization of science to develop interest and lasting passion for its pursuit, is a major concern across the world. There have been many initiatives to address the issue in India too. The meaning and role of 'Science Education' are being redefined to develop 'Scientific Temper' and 'Science Literacy' as overarching goals rather than merely providing knowledge related to the content of science. The implications of this hinge on the teachers, since they are the key persons responsible for transacting the teaching - learning process in the classroom.

Sherman and MacDonald [1] in their study report about the implementation and modification of science kits by the elementary school teachers in a rural set up of Canada. This was an initiative under the professional development of teachers and it was reported that the teachers shared a new confidence in teaching science. Many elementary teachers, particularly at the upper grades, feel challenged with science teaching [2]. Professional development can have a positive impact on teachers' pedagogical content knowledge 3], especially when it occurs on a continuous basis[4]. One challenge for many elementary teachers is a lack of previous experience with hands-on science [2]. Furthermore, many tend to make limited use of hands-on or inquiry activities in their classroom teaching [5]. The curriculum framework for teacher education [6]envisages the teacher to be actively involved in the 'development' of learner-centric, contextualized and sensitive-tocontemporary -situations resource material.

In generating excitement and interest in science through hands on activities, the role of 'science kits' as resource material has long been cognized since 50's and early 60 's. There was a strong thrust (initiating, in USA and UK) on learning science by doing. However, the scenario has not been a very encouraging one in the Indian context. Same is the case in many other developing countries. What can be seen as a widespread trend is that science kits don't find their desired place in science classrooms. However, in recent times, what is observed is that the school, as well as the teacher education curricula place a demand and expectations on the teacher that requires her to ensure that her learners become co-constructors of knowledge. Thus teachers must have the competence to evaluate and adapt existing science kits or develop new ones. It was in this background that the project was situated.

\subsection{Research Questions}

- What are the pedagogical, learner-based and contextual dimensions that make a science kit userfriendly in learning and popularization of science?

- How can these dimensions be developed into a framework through the identification of parameters that can be assessed? 


\section{Method}

As a preparatory task, an attempt was made to develop a compendium on science kits through documentary analysis as well as 'preliminary profiling' of the science kits sampled from various sources across the country.

\subsection{Profiling of Science Kits}

The science kits explored were classified under the broad categories as:

\section{Level-Based Science Kits}

The science kits relate directly to the different levels of the formal school science curriculum., the National Council of Educational Research and Training (NCERT) developed a number of science kits as:i)Primary Science Kits (PSK) : The kit is of the size of a medium size briefcase and has about 90 items in it. The kit enables the performing of more than 300 activities.(taken as sample for analysis by the research team)ii)Upper Primary Science Kits (UPSK) : It is a vertical box with shutter doors. The kit has around 130 items and offers a scope to perform more than 200 activities for classes VI - VIII.( taken as sample for analysis by the research team) iii) Secondary Science Kit (SSK) : Made on the same pattern as the Upper Primary Science Kit, this kit also contains around 130 items enabling the performing activities and experiments relevant in class IX-X curriculum.( taken as sample for analysis by the research team iv) Senior Secondary Science kits (classes XI-XII): a) Microscale Chemistry Laboratory Kit (taken as sample for analysis by the research team) b) Solid State Model Kitc) Molecular Model Kit

The Science kits prepared by 'Eklavya'(an NGO) under the Hoshangabad Science Teaching Programme had an innovative approach and mainly used indigenous materials. These kits had relevance to the upper primary science curriculum being taught in schools of Madhya Pradesh. These are few of the many other instances of curriculum related science kits.

\section{Theme-Based Science Kits}

There are many organizations across the country, developing science kits to popularize science among the people through informal set-ups. The purpose here is to create awareness through activities based on themes which relate to general interests, environmental issues and current situations thereby developing 'Science Literacy' and 'Scientific Temper' among the masses.

The National Council for Science and Technology Communication (NCSTC) under the Ministry of Science \& Technology through its network across the country supports the development of theme-based science kits to promote a better communication of scientific ideas and processes.

Some of the theme-based science kits were:

i) Micro-organisms : let us observe and learn (taken as sample for analysis by the research team)

ii) Vermiculture kit(taken as sample for analysis by the research team)

iii) Science Behind Miracles ( Developed in parallel by a student group also)

iv) Detection of Food Adulteration(taken as sample for analysis by the research team)

v) Weather Kit(taken as sample for analysis by the research team)

vi) Aerodynamics Kit

vii) Social Insects(taken as sample for analysis by the research team)

viii) Construction Technology Kit(taken as sample for analysis by the research team)

ix) Physics of Human Eye

$\mathrm{x}) \quad$ Solar Eclipse Kit(taken as sample for analysis by the research team)

xi) Model Rocketry kit

xii) Physics in Everyday Life (taken as sample for analysis by the research team)

Similarly, UNESCO also supported the development of Science Kits based on themes of general interest. Some of the kits were:
i) $\quad$ Micro science Kit
ii) Ozone Action
iii) Game kit on wetlands and water
iv) Environmental Education

UNESCO has compiled guiding modules to carry out experiments and activities adaptable to local needs. These packages transcend subject boundaries and can be used in Mathematics and Social Science too.

The theme-based science kits stretch beyond the confines of formal school levels. Some of the community based packages involve adult and children both. 


\section{Need based Science Kits}

These science kits were developed for and cater to special needs and situations.

i) A Science Kit prepared by the Homi Bhabha Centre for Science Education (HBCSE) was meant for earth- quake affected children in Maharashtra where the schools were destroyed in the disaster.

ii) Another Science Kit was developed by HBCSE for school drop outs, named 'You Can Do It'.

The project team (comprised of four science teachers and six teacher educators) through a series of workshops, working on twelve science kits (sampled from the kits mentioned above) developed the framework for assessing the pedagogic usefulness of science kits and the accompanying support material. The framework was evolved under six dimensions and each dimension included a number of parameters as mentioned below.

\subsection{Assessment of Science Kit Parameters}

\section{The Developed Framework}

1. Science Kit Material - familiarity, local availability/replaceability, usable by children or to be handled under supervision (The kit material includes objects / equipments / substances).

2. Pedagogic Soundness of the Science Kit-do the kit activities arouse curiosity and interest in science, do they foster a sound understanding of the related science concepts, do the kit activities promote the various science process skills (handling equipments, observing, recording observations, inferring, predicting, generalsing etc.), scope for leading to newer activity areas, do the kit activities lead to a meaningful construction of knowledge, an interdisciplinary understanding. If the kit can be used by/for differently abled / challenged learners.

3. Operational Management of the Science Kit - is the material too fragile to be handled, is the material labeled for better understanding and handling, can the kit be easily packed after use, is the size of container suitable to keep all the material conveniently, are there separate compartments for keeping the material, whether the compartments labeled for keeping the requisite material, if the kit portable.

4. Eco-friendliness of Components of the Science Kit - is most of the material eco-friendly, if not then can it be replaced by eco-friendly materials, any materials that are bio-degradable, any toxic materials, pollution causing materials, reusable materials.

5. Science-Popularisation Potential of the Kit - do the kit activities help in promoting awareness and popularization of science in community, can the kit activities be related to indigenous practices prevailing in community, can the kit be handled by community members also, do the kit activities address common misconceptions/problems/issues in daily life.

6. Cost effectiveness of Science kit - is the majority of material inexpensive/indigenous/improvisable/usable for long duration.

\subsection{Assessment of Support Material Parameters}

1. Pedagogic Support - does the support material explicitly spell out the objectives of the kit, arouse curiosity, take up related concepts, explain/suggest how activities develop science process skills and thinking skills, scope for further activities, interdisciplinary understanding, relatedness to daily life issues/problems/misconceptions, does the support material inform about multiple uses of kit items, about any research done in related area, does it include multimedia/ICT based materials.

2. Communicability - is the language of the support material simple and engaging, are there suitable pictorial representations.

3. Facilitation - if the support material familiarizes and mentions the specific usage of kit items, stimulates users to explore some other possible usage of kit items.

4. Operational Support - if there is a catalogue of materials along with labels, handling precautions/sources of error clearly mentioned, whether the shelf life/expiry of the perishable items mentioned, are the sources for procuring kit items suggested, are the alternatives for replaceable items suggested, are there instructions as to how the kit could be used for/by differently abled/challenged learners.

5. Community Sensitisation - if the support material explains/suggests how kit activities address common misconceptions/promote awareness/facilitate uses of local/indigenous /improvised materials, provisions/instructions for usage by community members.

6. Eco-friendly focus - if the support material highlights the eco -friendly materials in the kit, suggests usage of alternative eco-friendly materials, if it warns about the toxic nature of kit material(s) if any, about bio-degradable and non bio-degradable components of the kit, about the re-usability of products/residues of one activity in another 
The above mentioned six dimensions have been considered in an integrated manner. These guidelines were field-tested in schools and teacher education institutions in three different states of India as this was a national level project.

\section{Findings}

It was found that theme-based science kits had more appeal than level based kits which were quite bulky, almost like mini laboratories. The theme based approach was seen to enhance user-friendliness in terms of compactness of materials and activities. The new kits developed by teachers were all theme-based.

The science kits with smaller apparatus (easy to handle) and lesser chemicals (eco-friendly) usage were appreciated. This would be a step towards making science experimentation more environment friendly.

The nature of material in a Science Kit also matters in terms of its local availability and improvisational potential as opposed to sophisticated equipments which are difficult to procure. Many of the kits have motivational appeal because their materials are picked up from daily use objects. This makes them more costeffective too. The new kits developed by teachers met this requirement significantly.

The versatility of a science kit among diverse learner groups/contexts could be enhanced by grading the activities with a science kit into :

i. $\quad$ Familiarization level activities

ii. Enrichment level activities

By doing so, the same science kit could be used across a wide spectrum of learner groups.

The science kit ought to have some activities for physically/mentally challenged learners too along with other activities.

The kit manuals/support material should have formats and language different from text books, preferably, it should be interactive to motivate self learn

\section{Conclusion}

The science kits undoubtedly have the advantage of providing the required equipments and materials at one place and can be used in any type of set-up since they are self contained and portable. They hold the potential to stimulate learners cognitively and emotionally, enabling them to develop their science-process skills and thinking skills in a joyful exploratory manner. If all these are the strengths to support the science kits, then they need to find an appropriate place in the eco-system of a science classroom. This would happen only when teachers feel comfortable using the science kits and become so motivated that they think of developing their own kits, perhaps, involving their learners too. Teachers would then begin to take ownership of the kit development process by suggesting modifications, developing alternate activities using kit materials, and accommodating the specific needs of their students. In this project as teachers took on the creation of new kits or suggested modification of kit activities, changes in their interaction were noted. The exploration of the pedagogic usefulness of science kits brought forth the assessable dimensions and parameters that a teacher could relate with through her/his pedagogical understanding and learner group context. There is thus a considerable potential to build this up in all teacher development programmes.

\section{References}

[1] A. Sherman and A. L. MacDonald, The Use Of Science Kits in the Professional Development of Rural Elementary School Teachrs, Scienc Education Review,7(3), (2008).

[2] A. L. MacDonald and A.Sherman, Pre-service teachers' experiences with a science education module,Journal of Science Teacher Education, 18, (2007),525-541.

[3] A. L. MacDonald and A.Sherman, Children's perspectives on building science models, Education 3 to 13, (2006).

[4] J. Koch and K. Appleton, The effect of a mentoring model for elementary science professional development, Journal of Science Teacher Education, 18, (2007). 209-231.

[5] D. Goodrum, M.Hackling and L.RennieThe status and quality of teaching and learning of science in Australian schools. Canberra: Commonwealth of Australia, (2001).

[6] National Council for Teacher Education, National Curriculum Framework for Teacher Education.,New Delhi,(2010) www.ncteindia.org/ 